\title{
Hydrogen production by means pyrolysis and steam gasification of glycerol
}

\author{
J. M. Encinar ${ }^{1}$, J. F. González ${ }^{2}$, G. Martínez ${ }^{1}$, N. Sánchez ${ }^{1}$ and I. M. Sanguino ${ }^{1}$ \\ ${ }^{1}$ Dpto. Ingeniería Química y Química Física \\ Universidad de Extremadura \\ Campus de Badajoz - Avda. Elvas s/n, 06071 Badajoz (Spain) \\ Phone number:+0034 924 289672, Fax number:+0034924 289385, e-mail: jencinar@unex.es, \\ ${ }^{2}$ Dpto. Física Aplicada, Universidad de Extremadura \\ Campus de Badajoz - Avda. Elvas s/n, 06071 Badajoz (Spain)
}

\begin{abstract}
The objectives of this work were to optimize the variables affecting pyrolysis and steam gasification of glycerol (by-product formed during biodiesel production); and to characterize the gaseous phase formed, in order to carry out its energetic use. The studied operation variables were reaction temperature $\left(700-900{ }^{\circ} \mathrm{C}\right)$, water flow rate $\left(0-0.173 \mathrm{~g} \cdot \mathrm{min}^{-1}\right)$, glycerol flow rate $\left(0.009-0.676 \mathrm{~g} \cdot \mathrm{min}^{-1}\right)$ and carrier gas (nitrogen) flow rate $\left(30-180 \mathrm{~cm}^{3} \cdot \mathrm{min}^{-1}\right)$. The most interesting phase (analyzed by gas chromatography) was the gas fraction. In this work, gas fraction was composed by $\mathrm{H}_{2}, \mathrm{CH}_{4}, \mathrm{CO}, \mathrm{C}_{2} \mathrm{H}_{6}$, $\mathrm{C}_{2} \mathrm{H}_{4}$ and $\mathrm{CO}_{2}$. The main gas generated was the hydrogen. Its generation was favoured by steam presence and its yield was increased in $224 \%$ in relation with pyrolysis process (default of water steam). The better conditions for studied process were 800 ${ }^{\circ} \mathrm{C}, 0.074 \mathrm{~g} \cdot \mathrm{min}^{-1}$ of water flow rate, $0.009 \mathrm{~g} \cdot \mathrm{min}^{-1}$ of glycerol flow rate and $60 \mathrm{~cm}^{3} \cdot \mathrm{min}^{-1}$ of nitrogen flow rate. In these conditions, the volume of synthesis gas was $1.86 \mathrm{~L} \cdot\left(\mathrm{g}_{\text {glycerol }}\right)^{-1}$ and its higher heating value (HHV) was $26.70 \mathrm{MJ} \cdot\left(\mathrm{kg}_{\text {glycerol }}\right)^{-1}$. This study indicated that the bio-glycerol is an excellent raw material in the obtaining of medium heating value gases. These gases could be used as fuel in industrial furnaces or domestic use.
\end{abstract}

\section{Key words}

Hydrogen production, glycerol, pyrolysis, steam gasification.

\section{Introduction}

Biodiesel is an alternative fuel to petrodiesel technically feasible, economically competitive, environmentally acceptable and easily available. For these reasons, biodiesel is attracting increasing attention world wide as a blending component or a direct replacement for diesel fuel in vehicle engines [1]. Globally, current energy policies reflect environmental issues including developing environmentally friendly technologies and increasing energy security and clean energy supplies. The implementation of the current directives about biodiesel triggers a huge demand for biodiesel [2].
The main way to make biodiesel is the transesterification of vegetable oils and animal fats. In this way the triglycerides from the feedstock react with a short-chain alcohol to form fatty acid methyl ester and glycerol. The reaction turn a mol of triglyceride into a mol of glycerol, in fact, 100 tons of glycerol per 1000 tons of biodiesel are obtained when transesterification occurs [1]. Glycerol is a highly versatile product and has a lot of uses. Almost two third of the industrial uses of glycerol are in food and beverage $(23 \%)$, personal care $(24 \%)$, oral care $(16 \%)$ and tobacco (12\%) [3]. In this way, the glycerol marketing would have a positive impact on the biodiesel manufacturing cost. However, the increasing available amount of glycerol due to the rapid growth of the biodiesel production has provoked a huge excess in glycerol market. In fact, the worldwide production of glycerol was more than 0.9 million tons in 2006, and in 2010 its production is estimated as high as 1.2 million tons [4]. This huge excess triggers glycerol market price depreciation because of this market is unable to absorb high amounts of the product. For these reasons and because of the glycerol contains impurities, the biodiesel industries are managing the glycerol excess as a waste. Therefore they suffer the impact of the increasing storage and management costs [5]. Taking into account these problems, it is important to explore other alternatives able to valorize high amount of glycerol. One of these glycerol valorization alternatives is its conversion into hydrogen.

Hydrogen is an environmentally friendly fuel as a feedstock for ammonia-based fertilizers or other chemicals as well as is gaining widespread applications with the advent of fuel cell technologies. At present, almost $95 \%$ of the world's hydrogen is produced from fossil fuels, hence, to develop an alternative source of hydrogen is very interesting [6]. Glycerol is a potential feedstock to produce hydrogen because $1 \mathrm{~mol}$ of glycerol can theoretically produce up to $4 \mathrm{~mol}$ of hydrogen. The main methods for the production of hydrogen from 
glycerol are pyrolysis [7-9], steam reforming [10-12], dry reforming [13], autothermal reforming [14], aqueousphase reforming [15] and supercritical water reforming [16].

Pyrolysis consists of the oxygen free thermal cracking of substance and at high temperature; the obtained products are in the three phases: gaseous, liquid and solid. Gas phase is composed mainly by hydrogen, carbon monoxide, carbon dioxide and methane, the liquid phase is composed by hydrocarbons like ethylene, acetylene, and the solid phase is char. The most important phases are gas and liquid [7]. Gas fraction is normally the most important and usually content high amount of $\mathrm{H}_{2}$ or high amount of the mixture $\mathrm{H}_{2}+\mathrm{CO}$ (synthesis gas). Syngas could be used as a feedstock in Fischer-Tropsh synthesis to produce green diesel (long chain hydrocarbon). Pyrolysis has been studied by different authors; for example, Valliyappan et al.[8] carried out the pyrolysis of glycerol; it was observed that temperature, carrier flow rates and particle diameter of packing material had profound effects on the conversion of glycerol as well as product distribution. Moreover, this study indicated that the glycerol has potential in making syngas and medium heating value gases. Pyrolysis of mixtures of bio-oil and glycerol was also reported [9].

On the other hand, the steam reforming or steam gasification is the most commonly used method for producing hydrogen in the chemical industry. In this process, the substrate is reacted with steam, the gasifying agent, to produce, as by pyrolysis, hydrogen, carbon monoxide, carbon dioxide and methane, and to a lesser extent liquid and solid phases [10]. Thermodynamic analysis of steam gasification of glycerol has been performed, founding that the process at atmospheric pressure is favoured in high temperature and high water/glycerol ratio, having this parameter the most important effect on $\mathrm{H}_{2}$ yield. Under these conditions methane production is minimized and the carbon formation is thermodynamically inhibited. Moreover, glycerol with possible contaminants (chloride and sodium ions) present in crude glycerine as byproducts of biodiesel synthesis was tested in the reformer, producing similar results $[17,18]$. On the other hand, catalytic steam has been tested. This process gets the valorization of glycerol in economic and effective way. The catalysts usually used are metal supported on metallic oxides [19].

The aim of this study is to produce hydrogen by pyrolysis and steam gasification of glycerol and, in this way, to revalorize the byproduct of biodiesel.

\section{Materials and Methods}

\section{A. Experimental Section}

Glycerol (PRS) was supplied by Panreac and $\alpha$-alumina with diameter $20 \mathrm{~mm}$ (filler material), by Keratec Advanced Materials S.A. Carrier gas $\left(\mathrm{N}_{2}, 5.0\right)$ and gases for chromatograph calibrate $\left(\mathrm{H}_{2} 5.0, \mathrm{CH}_{4} 3.5, \mathrm{CO} 3.7, \mathrm{CO}_{2}\right.$ 4.5, $\mathrm{C}_{2} \mathrm{H}_{4} 2.8, \mathrm{C}_{2} \mathrm{H}_{6} 2.5$ ) were supplied by Linde.

Experimental set-up, similar to previous works $[20,21]$ is shown in Figure 1. Reactor consisted of a cylindrical tube of stainless steel 316. It was arranged vertically and its sizes were $75.5 \mathrm{~cm}$ longitude, $5.2 \mathrm{~cm}$ internal diameter and $6.0 \mathrm{~cm}$ outer diameter. At the top, it had a suspension system of the basket where filler material ( $\alpha$-alumina) was contained, maintaining the tightness of system. Also at the top were located, on the one hand, $\mathrm{N}_{2}$ gas and water-glycerol solution feeding systems; and on the other hand, the thermocouple for temperature control inside reactor. After the first reactor was a second reactor in series. The aim of this was to increase residence time at reaction temperature. Its dimensions were $36.0 \mathrm{~cm}$ longitude, $5.2 \mathrm{~cm}$ internal diameter and $6.0 \mathrm{~cm}$ outer diameter. It also contained a thermocouple for temperature control and accessories to collect liquid and gas phases. Reactors were provided with heating systems, consisting of ceramic furnace and power source. Temperature was controlled to within $\pm 2{ }^{\circ} \mathrm{C}$ automatically, and all experiments were carried out isothermally.

Each experiment consisted of pyrolysis-gasification of a glycerol solution. Water-glycerol flow rate was supplied to the system using a KONIC pump, calibrated previously. In first reactor, the basket filled with porous material (alpha alumina) was located. The role of porous material was to increase the contact surface between glycerol and water vapor. Following the launch of carrier gas flow rate, heating system was connected at programmed temperature reaction. Once temperature was reached, water-glycerol feeding system was connected to desired flow.

At this time, samples of non-condensable gases were analyzed chromatographically until concentrations remained constant, that is, until steady state.

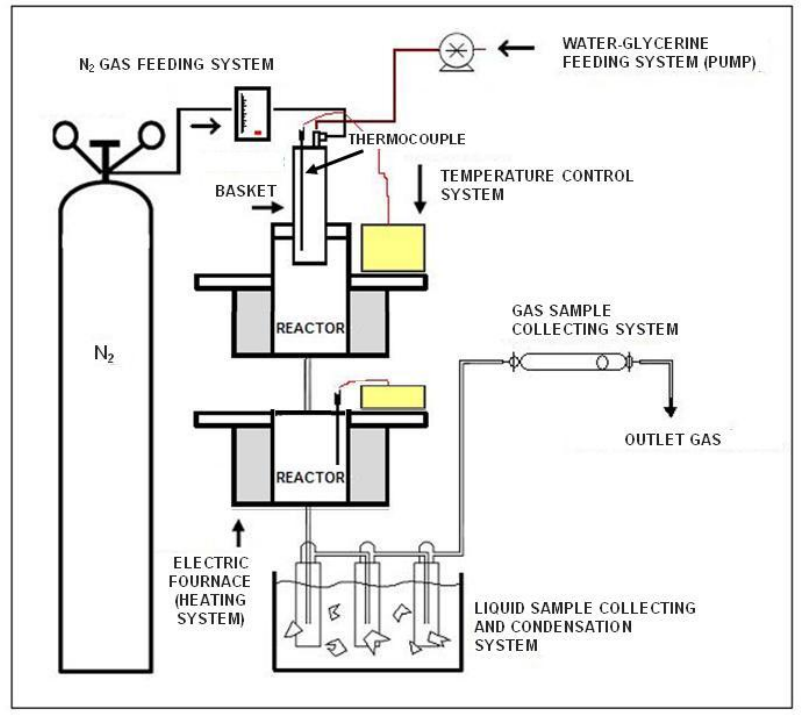

Fig. 1. Experimental set-up.

\section{B. Product analysis}

Gas phase was assayed by gas chromatography in a VARIAN 3900 chromatograph, provided with a thermal conductivity detector and automatic injector by airactuated valve (Valco 2 positions). Silica semi-capillary column of $50 \mathrm{~m}$ length, $0.53 \mathrm{~mm}$ ID, and $0.50 \mu \mathrm{m}$ film thickness was employed. Carrier gas was argon at a flow rate of $0.7 \mathrm{~mL} \cdot \mathrm{min}^{-1}$. Injector temperature was kept at $200{ }^{\circ} \mathrm{C}$, and the detector temperature, $160{ }^{\circ} \mathrm{C}$. Temperature ramp starts with $40{ }^{\circ} \mathrm{C}$ during $7 \mathrm{~min}$, then 
$55^{\circ} \mathrm{C} \cdot \mathrm{min}^{-1}$ up to $150^{\circ} \mathrm{C}$ during $20 \mathrm{~min}$.

On the other hand, higher heating value, HHV, of syngas was calculated. Heating value of fuel is the amount of heat released in complete combustion of a fuel unit, $1 \mathrm{~kg}$ if it is a solid or liquid fuel and $1 \mathrm{~m}^{3} \mathrm{~N}$ (at $0{ }^{\circ} \mathrm{C}$ and $760 \mathrm{mmHg}$ ) in the case of a gaseous fuel. Gaseous fuels are mixtures of simple combustible components, and therefore, its heating value is deduced with sufficient precision and accuracy from the percentage volume composition by its heats of combustion. Knowing the composition of gas produced $\left(\mathrm{H}_{2}, \mathrm{CO}, \mathrm{CH}_{4}, \mathrm{C}_{2} \mathrm{H}_{6}, \mathrm{C}_{2} \mathrm{H}_{4}\right.$ and $\left.\mathrm{CO}_{2}\right)$, we should take into account the following combustion reactions:

$$
\begin{array}{rr}
\mathrm{CO}+1 / 2 \mathrm{O}_{2} \rightarrow \mathrm{CO}_{2} & +0.2827 \mathrm{MJ} / \mathrm{mol} \\
\mathrm{H}_{2}+1 / 2 \mathrm{O}_{2} \rightarrow \mathrm{H}_{2} \mathrm{O}_{(l)} & +0.2856 \mathrm{MJ} / \mathrm{mol} \\
\mathrm{CH}_{4}+2 \mathrm{O}_{2} \rightarrow \mathrm{CO}_{2}+2 \mathrm{H}_{2} \mathrm{O}_{(l)} & +0.8895 \mathrm{MJ} / \mathrm{mol} \\
\mathrm{C}_{2} \mathrm{H}_{6}+7 / 2 \mathrm{O}_{2} \rightarrow 2 \mathrm{CO}_{2}+3 \mathrm{H}_{2} \mathrm{O}_{(l)} & +0.1561 \mathrm{MJ} / \mathrm{mol} \\
\mathrm{C}_{2} \mathrm{H}_{4}+3 \mathrm{O}_{2} \rightarrow 2 \mathrm{CO}_{2}+2 \mathrm{H}_{2} \mathrm{O}_{(l)} & +0.1411 \mathrm{MJ} / \mathrm{mol}
\end{array}
$$

According to the above, $\mathrm{HHV}\left(\mathrm{MJ} \cdot \mathrm{kg}_{\text {glycerol }}{ }^{-1}\right)$ is given by equation (6):

$$
\begin{aligned}
H H V & =0.2827 \cdot n C O+0.2856 \cdot n H_{2}+0.8895 \cdot n C_{4}+ \\
& 0.1561 \cdot n C_{2} H_{6}+0.1411 \cdot n C_{2} H_{4}
\end{aligned}
$$

where $n X$ represents mols of each gas generated per $1 \mathrm{~kg}$ of glycerol.

\section{Results and Discussion}

The studied operation variables were reaction temperature $\left(700,800,850,900{ }^{\circ} \mathrm{C}\right)$, water flow rate $(0,0.030,0.074$, $\left.0.173 \mathrm{~g} \cdot \mathrm{min}^{-1}\right)$, glycerol flow rate $(0.009,0.030,0.074$, $\left.0.173,0.676 \mathrm{~g} \cdot \mathrm{min}^{-1}\right)$ and carrier gas flow rate $(30,60$, $\left.120,180 \mathrm{~cm}^{3} \cdot \mathrm{min}^{-1}\right)$.

As mentioned previously, three phases (gas, liquid and solid) are obtained from the pyrolysis and gasification processes of organic matter. However, since the objective of this research is hydrogen production, the presentation and discussion of results will primarily focus on gas phase production and its composition.

Solid phase consists of solid residue formed in small quantities on filler material, and liquid fraction consists of complex organic products, mainly tars, and it was collected together with water process.

As had been indicate the gas fraction, analyzed chromatographically, was mainly composed by $\mathrm{H}_{2}, \mathrm{CH}_{4}$, $\mathrm{CO}, \mathrm{C}_{2} \mathrm{H}_{6}, \mathrm{C}_{2} \mathrm{H}_{4}$ and $\mathrm{CO}_{2}$.

\section{A. Temperature influence}

To study temperature influence, experiments at 700, 750, 800 and $900{ }^{\circ} \mathrm{C}$ were tested. In all cases we employed water-glycerol total flow rate of approximately 0.247 $\mathrm{g} \cdot \mathrm{min}^{-1}$, with $30 \%$ by weight of glycerol $\left(0.074 \mathrm{~g} \cdot \mathrm{min}^{-1}\right)$ and carrier gas flow rate was set at $60 \mathrm{~cm}^{3} \cdot \mathrm{min}^{-1}$. Specific values of mass and volume flow rates, used in each experiment, are reflected in figure captions.

Figure 2 shows temperature effect on syngas composition during gasification of glycerol. It can be seen that $\mathrm{H}_{2}$ production changed from 35 to $50.3 \%$ when temperature increased from 700 to $800{ }^{\circ} \mathrm{C}$, and then it remained constant from this temperature.

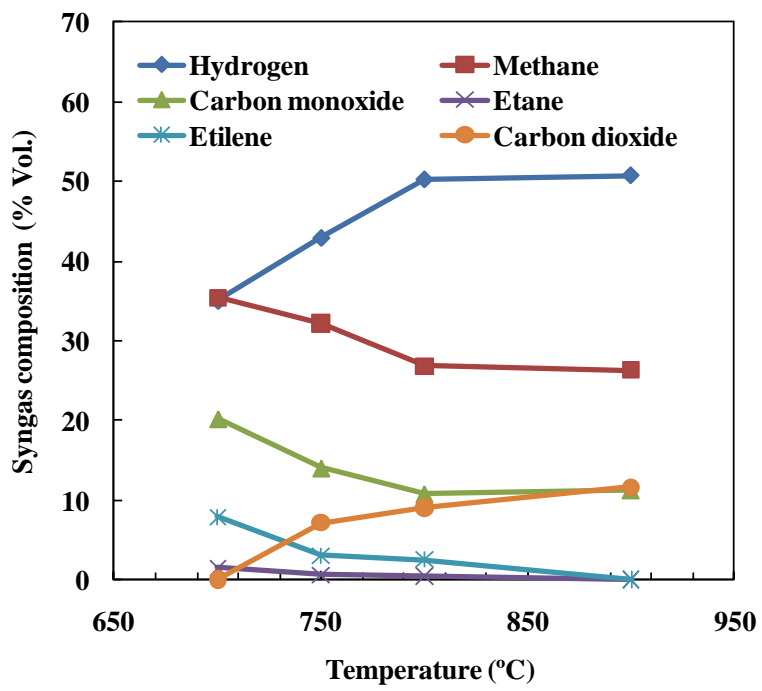

Fig. 2. Influence of temperature on syngas composition. Reaction conditions: water flow rate, $0.173 \mathrm{~g} \cdot \mathrm{min}^{-1}$; glycerol flow rate, $0.074 \mathrm{~g} \cdot \mathrm{min}^{-1}$; carrier gas flow rate, $60 \mathrm{~cm}^{3} \cdot \mathrm{min}^{-1}$.

However, $\mathrm{CO}$ production at $700{ }^{\circ} \mathrm{C}$ was $20.22 \%$, decreasing to $10 \%$ at $800{ }^{\circ} \mathrm{C}$, after which it remained almost unchanged. On the other hand, hydrocarbons production decreased when temperature increased: $\mathrm{CH}_{4}$ production was reduced from 35.43 to $17.54 \%, \mathrm{C}_{2} \mathrm{H}_{6}$ production of 1.46 to $0 \%$ and $\mathrm{C}_{2} \mathrm{H}_{4}$ production of 7.88 to $0 \%$ when the temperature increased from 700 to $900{ }^{\circ} \mathrm{C}$. Thus, an increase in temperature from 700 to $800{ }^{\circ} \mathrm{C}$ gave rise to an increase in $\mathrm{H}_{2}$ and $\mathrm{CO}_{2}$ productions, while for the rest there was a decline. These facts are due to cracking suffering by glycerol and hydrocarbons of low boiling when temperature increases. Specifically, the increase in $\mathrm{H}_{2}$ production could be due to decomposition of hydrocarbons $\mathrm{CH}_{4}, \mathrm{C}_{2} \mathrm{H}_{6}$ and $\mathrm{C}_{2} \mathrm{H}_{4}$ to coke and to $\mathrm{H}_{2}$, as reflected in the reaction (7) $[8,22-24]$. Moreover, this explains the decrease in generation of $\mathrm{CH}_{4}, \mathrm{C}_{2} \mathrm{H}_{6}$ and $\mathrm{C}_{2} \mathrm{H}_{4}$, and even the total decomposition of $\mathrm{C}_{2} \mathrm{H}_{6}$ and $\mathrm{C}_{2} \mathrm{H}_{4}$ at $900{ }^{\circ} \mathrm{C}$.

$$
C_{x} H_{y} \Leftrightarrow m H_{2}+n C_{s}
$$

From $800{ }^{\circ} \mathrm{C}$ syngas composition remained almost unchanged, however volume of syngas and percentage of glycerol converted were significantly improved at $900{ }^{\circ} \mathrm{C}$ (see Table I). That is, when temperature increased from 800 to $900{ }^{\circ} \mathrm{C}$, the amount of glycerol converted was increased; thereby obtaining a syngas volume higher, but its composition was practically identical to composition of syngas obtained at $800{ }^{\circ} \mathrm{C}$.

As can be seen in Table I, higher heating value of syngas increased when reaction temperature was increased. As explained previously, HHV of gases is a function of moles of $\mathrm{H}_{2}, \mathrm{CO}, \mathrm{CH}_{4}$ and other hydrocarbons, produced per kilogram of pure raw material (see equation (6)). Although $\mathrm{CO}$ and $\mathrm{CH}_{4}$ productions decreased in the syngas, amount of this gas phase increased with temperature. Therefore, quantitatively the amount of these three gases increased, causing an increase in HHV global of gas obtained. 
Table I.- Operating conditions and results in steam gasification of glycerol.

\begin{tabular}{|c|c|c|c|c|c|c|}
\hline \multicolumn{4}{|c|}{ OPERATING CONDITIONS } & \multicolumn{3}{|c|}{ RESULTS } \\
\hline $\mathbf{T},{ }^{\circ} \mathbf{C}$ & $\begin{array}{l}\text { Water, } \\
\text { g. } \text { min }^{-1}\end{array}$ & $\begin{array}{c}\text { Glycerol, } \\
\mathbf{g} \cdot \text { min }^{-1}\end{array}$ & $\begin{array}{c}\text { Carrier } \\
\text { gas, } \\
\mathrm{cm}^{3} \cdot \mathbf{m i n}^{-1}\end{array}$ & \begin{tabular}{|c|} 
Glycerol \\
reacted \\
yield, \%
\end{tabular} & $\begin{array}{c}\text { Gas } \\
\text { volume, } \\
\mathbf{L} \cdot \mathbf{g}_{\text {glycerol }}\end{array}$ & $\begin{array}{l}\text { HHV gas, } \\
{\mathrm{MJ} \cdot \mathrm{kg}_{\text {glycerol }}}^{-1}\end{array}$ \\
\hline 700 & 0.173 & 0.074 & 60 & 73.46 & 0.79 & 15.22 \\
\hline 750 & 0.173 & 0.074 & 60 & 78.64 & 1.03 & 18.95 \\
\hline 800 & 0.173 & 0.074 & 60 & 83.26 & 1.26 & 21.28 \\
\hline 900 & 0.173 & 0.074 & 60 & 97.98 & 1.59 & 26.70 \\
\hline 800 & 0 & 0.074 & 60 & 81.51 & 1.14 & 15.08 \\
\hline 800 & 0.030 & 0.074 & 60 & 85.66 & 1.23 & 17.68 \\
\hline 800 & 0.074 & 0.074 & 60 & 91.89 & 1.35 & 20.59 \\
\hline 800 & 0.074 & 0.009 & 60 & 92.20 & 1.83 & 25.64 \\
\hline 800 & 0.074 & 0.030 & 60 & 96.17 & 1.45 & 20.86 \\
\hline 800 & 0.074 & 0.173 & 60 & 70.43 & 0.92 & 15.80 \\
\hline 800 & 0.074 & 0.676 & 60 & 75.55 & 0.88 & 16.45 \\
\hline 800 & 0.074 & 0.009 & 30 & 93.32 & 1.86 & 26.39 \\
\hline 800 & 0.074 & 0.009 & 120 & 64.74 & 1.24 & 14.04 \\
\hline 800 & 0.074 & 0.009 & 180 & 54.78 & 0.93 & 9.35 \\
\hline
\end{tabular}

Taking $\mathrm{H}_{2}$ production as variable to maximize, the optimal temperature would be $900{ }^{\circ} \mathrm{C}$. It is even doubt what would have happened if the temperature had increased even more. However, we must take into account the limitations of reactor materials and their wear with increasing temperature. Another consideration, obviously, is the energy expenditure. In these circumstances, we opted for a compromise situation, choosing a temperature of $800{ }^{\circ} \mathrm{C}$ to carry out the study of the other variables influence.

\section{B. Water flow rate influence}

In this series, all experiments were performed at $800{ }^{\circ} \mathrm{C}$ with a nitrogen flow rate of $60 \mathrm{~cm}^{3} \cdot \mathrm{min}^{-1}$ and glycerol flow rate of $0.074 \mathrm{~g} \cdot \mathrm{min}^{-1}$.

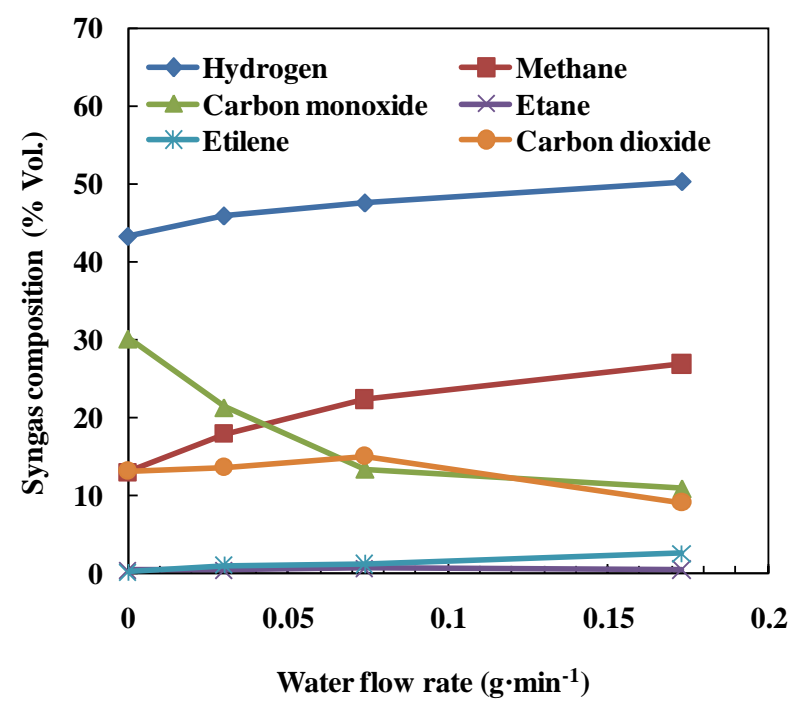

Fig. 3. Influence of water flow rate on syngas composition. Reaction conditions: temperature, $800^{\circ} \mathrm{C}$; glycerol flow rate, $0.074 \mathrm{~g} \cdot \mathrm{min}^{-1}$; carrier gas flow rate, $60 \mathrm{~cm}^{3} \cdot \mathrm{min}^{-1}$.
In Figure 3, effect of gasifying agent (steam) flow on composition of gas phase is shown. It is observed that there was a mild increase in $\mathrm{H}_{2}$ production (from 43.3 to $50.3 \%$ ) when amount of water was from 0 (pyrolysis) to $0.173 \mathrm{~g} \cdot \mathrm{min}^{-1} . \quad \mathrm{CO}_{2}$ production remained virtually constant. $\mathrm{CO}$ production decreased sharply (from $30.1 \%$ to $13.3 \%$ ) when glycerin increased from pyrolysis to gasifying with water flow rate of $0.074 \mathrm{~g} \cdot \mathrm{min}^{-1}$, when gasifying agent flow further increased, $\mathrm{CO}$ production continued to decline but more slow. Hydrocarbons production increased when water flow was increased. In the case of $\mathrm{C}_{2} \mathrm{H}_{6}$ and $\mathrm{C}_{2} \mathrm{H}_{4}$, this increase was not pronounced. However, $\mathrm{CH}_{4}$ production increased from $13 \%$ when the operation was performed without gasifying agent, to $26.9 \%$ when water flow rate was $0.173 \mathrm{~g} \cdot \mathrm{min}^{-1}$.

As can be seen in Table I, gas volume generated (1.35 $\left.\mathrm{L} \cdot \mathrm{g}_{\text {glycerol }}{ }^{-1}\right)$ and process yield $(91.89 \%)$ reached the maximum when water flow rate was $0.074 \mathrm{~g} \cdot \mathrm{min}^{-1}$. Probably, steam addition enhances the distribution of reagents through the filler material, causing a greater number of reactions and an improvement in the thermal cracking of glycerol. From this maximum, gas production and process yield decreased, probably due to a decrease in residence time of reagents when amount of water increased. The increase in $\mathrm{H}_{2}$ production and the decrease in $\mathrm{CO}$ production were probably due to the reaction occurring between $\mathrm{CO}$ and steam to produce $\mathrm{CO}_{2}$ and $\mathrm{H}_{2}$, water gas shift reaction (8).

$$
\mathrm{CO}+\mathrm{H}_{2} \mathrm{O} \Leftrightarrow \mathrm{CO}_{2}+\mathrm{H}_{2} \quad-41 \mathrm{~kJ} / \mathrm{mol}
$$

HHV of gas phase increased when water vapor was introduced into the system, up to a water flow rate of $0.074 \mathrm{~g} \cdot \mathrm{min}^{-1}$. This is because $\mathrm{CH}_{4}$ production doubled in the same interval. This gas has a HHV higher than $\mathrm{H}_{2}$ and $\mathrm{CO}$ and, consequently, an increase in total count of HHV was produced. From $0.074 \mathrm{~g} \cdot \mathrm{min}^{-1} \mathrm{HHV}$ increased but less sharply, because the main gases $\left(\mathrm{H}_{2}, \mathrm{CH}_{4}\right.$ and $\left.\mathrm{CO}\right)$ did not change over their productions.

The gas produced with the highest percentage in moles (or volume) of $\mathrm{H}_{2}$ was obtained with a water flow rate of $0.173 \mathrm{~g} \cdot \mathrm{min}^{-1}$. With a water flow rate of $0.074 \mathrm{~g} \cdot \mathrm{min}^{-1}$, a lower percentage of $\mathrm{H}_{2}$ was obtained in the gas mixture, but also a greater volume of gas was generated which leads to the relationship between them produced bigger amount of $\mathrm{H}_{2}$ per gram of glycerol. Thus, we chose a flow rate of $0.074 \mathrm{~g} \cdot \mathrm{min}^{-1}$ to carry out the study of the other variables.

\section{Glycerol flow rate influence}

All experiments, in this study, were performed at $800{ }^{\circ} \mathrm{C}$ with a nitrogen flow rate of $60 \mathrm{~cm}^{3} \cdot \mathrm{min}^{-1}$ and water flow rate of $0.074 \mathrm{~g} \cdot \mathrm{min}^{-1}$.

Figure 4 shows that as when glycerol flow rate was increased, $\mathrm{H}_{2}$ production decreased (from $60.3 \%$ to $36.2 \%$ across the range tested). $\mathrm{CO}_{2}$ production showed the same trend, however, the production of other gases increased when the amount of glycerol increased. This behavior could be because the water exerts a limiting effect as gasifying agent. Thus, by increasing glycerol flow rate, water flow rate remains in default, causing part 
of the glycerol undergo a thermal cracking, that is, a simple pyrolysis.

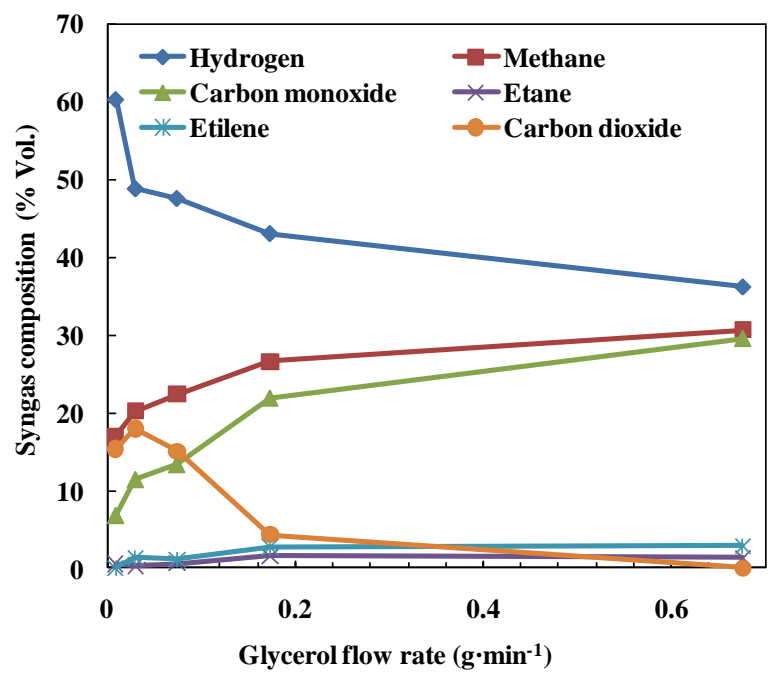

Fig. 4. Influence of glycerol flow rate on syngas composition. Reaction conditions: temperature, $800{ }^{\circ} \mathrm{C}$; water flow rate, 0.173 $\mathrm{g} \cdot \mathrm{min}^{-1}$; carrier gas flow rate, $60 \mathrm{~cm}^{3} \cdot \mathrm{min}^{-1}$.

In addition, increasing the ratio of glycerol/water flows are likely to impede the distribution of the reactants through the fill material, resulting in less intimate contact and worse reaction conditions. In this context, it should consider the main reactions involved in the reforming of glycerol with steam $[25,26]$. In addition to the reactions (7) and (8), we should consider the following:

$$
\begin{array}{rr}
\mathrm{C}_{3} \mathrm{H}_{8} \mathrm{O}_{3}+3 \mathrm{H}_{2} \mathrm{O} \Leftrightarrow 7 \mathrm{H}_{2}+3 \mathrm{CO}_{2} & +128 \mathrm{~kJ} / \mathrm{mol} \\
\mathrm{C}_{3} \mathrm{H}_{8} \mathrm{O}_{3} \Leftrightarrow 4 \mathrm{H}_{2}+3 \mathrm{CO} & +250 \mathrm{~kJ} / \mathrm{mol} \\
\mathrm{C}+\mathrm{H}_{2} \mathrm{O} \Leftrightarrow \mathrm{CO}+\mathrm{H}_{2} & +131 \mathrm{~kJ} / \mathrm{mol} \\
\mathrm{C}+2 \mathrm{H}_{2} \Leftrightarrow \mathrm{CH}_{4} & -75 \mathrm{~kJ} / \mathrm{mol} \\
\mathrm{CO}+3 \mathrm{H}_{2} \Leftrightarrow \mathrm{CH}_{4}+\mathrm{H}_{2} \mathrm{O} & -206 \mathrm{~kJ} / \mathrm{mol} \\
\mathrm{CO}_{2}+4 \mathrm{H}_{2} \Leftrightarrow \mathrm{CH}_{4}+2 \mathrm{H}_{2} \mathrm{O} & -165 \mathrm{~kJ} / \mathrm{mol} \\
\mathrm{C}+\mathrm{CO}_{2} \Leftrightarrow 2 \mathrm{CO} & +172 \mathrm{~kJ} / \mathrm{mol}
\end{array}
$$

In the experiments with glycerol flow rate equal or less than water flow rate, a yield of $93 \%$ was observed, whereas when glycerol flow rate exceeded water flow rate, yields fell to $70 \%$ (see Table I). These facts can be explained by reactions (9) and (10). According to (9), if water vapor is the limiting reagent, the hydrogen formation would be conditioned by this fact. In the absence of water vapor (or otherwise) reaction (10), regardless of their strong endothermic, acquire ownership, and this would explain the increasing of $\mathrm{CO}$ formation in syngas. Finally, (regardless of route pyrolysis) $\mathrm{CH}_{4}$ formation would be affected by reactions (12) to (14). Specifically, reaction (13) could be of key importance when operating in conditions where $\mathrm{CO}$ concentration is very high.

HHV of gas fraction decreased with increasing glycerol flow rate. As shown, the amount of $\mathrm{H}_{2}$ produced decreased and the amounts of $\mathrm{CH}_{4}$ and $\mathrm{CO}$ increased. However, the decrease rate of $\mathrm{H}_{2}$ production was much greater than the growth rate of $\mathrm{CH}_{4}$ and $\mathrm{CO}$ productions, causing a global decrease in $\mathrm{HHV}$ of syngas.
Given the amount of $\mathrm{H}_{2}$ produced as variable to maximize, we can conclude that must be operated in conditions of water vapor excess. Therefore, to carry out the study of carrier gas flow influence, we chose to work with $0.009 \mathrm{~g} \cdot \mathrm{min}^{-1}$ of glycerol.

\section{Carrier gas flow rate influence}

As is know, this variable is one of the most important for optimizing gasification processes because it is directly related to residence times $[8,16,27-29]$. In this experimental series, operating conditions were $800{ }^{\circ} \mathrm{C}$, water flow rate of $0.074 \mathrm{~g} \cdot \mathrm{min}^{-1}$ and glycerol flow rate of $0.009 \mathrm{~g} \cdot \mathrm{min}^{-1}$.

With regard to the composition of gas produced, it remained practically constant, only a slight decrease in $\mathrm{CH}_{4}$ and $\mathrm{H}_{2}$ productions were observed, when nitrogen flow rate was increased.

By increasing carrier gas flow rate, residence time of the components in the reactor decreases, which produces, on the one hand, a poor distribution of the reagents on the filler material and, secondly, a decrease in time reaction. This fact was reflected in the volume of gas phase and its yield, because they decreased when nitrogen flow rate was increased (see Table I). Moreover, as the nitrogen flow rate was increased, more amount of glycerol did not react, probably because his time spent in the reactor was too small to give it time to react.

Similarly, HHV of gas produced decreased when the carrier gas flow was increased. In this case, this decrease was due to a decrease in the amounts generated of $\mathrm{H}_{2}$ and $\mathrm{CH}_{4}$, and to a decline in the volume of gases generated per weight of glycerol.

When carrier gas flow rate was reduced below 60 $\mathrm{cm}^{3} \cdot \mathrm{min}^{-1}$ significant changes were not observed. Probably below this value, the residence time is sufficiently large so that process was chemically controlled, that is, residence time would ensure that the reagents could react at the speed of reaction that marked the thermodynamic conditions. Thus, in these conditions, an increase of gas volume and of its HHV could not be reached. Similarly, significant variations in the composition of syngas were not appreciated.

\section{Conclusions}

In the study of pyrolysis and steam gasification of glycerol, tested in this research, syngas was consisted of $\mathrm{H}_{2}, \mathrm{CH}_{4}, \mathrm{CO}, \mathrm{C}_{2} \mathrm{H}_{6}, \mathrm{C}_{2} \mathrm{H}_{4}$ and $\mathrm{CO}_{2}$, and $\mathrm{H}_{2}$ was the majority (and the objective of this research). Temperature and steam/glycerol flows relation exerted greater influence. Carrier gas flow rate did not significantly influence on products distribution, but it influenced on quantity and HHV of syngas: when carrier gas flow decreased, these increased.

An increase in reaction temperature produced a marked increase in gas fraction production. This was because condensable gases suffered a sharp cracking when temperature increased. In addition, increasing temperature favors the most interesting reactions to the process. As with the water flow, temperature had a positive influence across the range: quantity and HHV syngas increased always, and $\mathrm{H}_{2}$ production did it to 800 
${ }^{\circ} \mathrm{C}$ (at higher temperatures there was not variability in composition gas).

Presence of water vapor produced a notable increase in syngas yield, since the steam favors cracking of heavy hydrocarbons, reforming of methane and other reactions with carbonaceous solid residue. In fact, the increase in water/glycerol flows ratio gave rise to increased syngas production. Within range of variability used, water flow rate has always had a positive effect on the amount and HHV of syngas. Hydrogen increased its production by $224 \%$ in gasification process with respect to that produced in pyrolytic process (without water).

Volume of syngas ranged from 0.79 to $1.86 \mathrm{~L} \cdot\left(\mathrm{g}_{\text {glycerol }}\right)^{-1}$; and its HHV did it between 9.33 and $26.70 \mathrm{MJ} \cdot\left(\mathrm{kg}_{\text {glycerol }}\right)^{-1}$. Therefore, this study proves that bio-glycerol is suitable for generating syngas with medium calorific value by steam gasification. This gas could be used as fuel in industrial furnaces or domestic use.

Although $\mathrm{H}_{2}$ production obtained in this research was very high, it would be desirable to try different catalysts to increase the selectivity towards hydrogen formation from production of the rest.

\section{Acknowledgement}

The authors express their gratitude to the "MICINN" and the "Junta de Extremadura" for the financial support received to perform this study by means of Projects ENE2009-13881, PRI09B102 and PDT 09A037 respectively.

\section{References}

[1] A. Demirbas, "Progress and recent trends in biodiesel fuels", in Energy Conversion and Management, (2009), Vol. 50, pp. 1434.

[2] J. Janaun and N. Ellis, "Perspectives on biodiesel as a sustainable fuel", in Renewable and Sustainable Energy Reviews, (2010), Vol. 14, pp. 1312-1320.

[3] S. Claude, "Research of new outlets for glycerol - recent developments in France", in Lipid / Fett, (1999), Vol. 101, pp. 101-104.

[4] D. T. Johnson and K. A. Taconi, "The glycerin glut: Options for the value-added conversion of crude glycerol resulting from biodiesel production", in Environmental Progress, (2007), Vol. 26, pp. 338-348.

[5] M. Boyd, A. Murray-Hill and K. Schaddelee, "Biodiesel British Columbia. Feasibility study report." in Canada: WISE Energy Coop and EcoLiteracy, (2004).

[6] S. Dunn, "Hydrogen futures: toward a sustainable energy system", in International Journal of Hydrogen Energy, (2002), Vol. 27, pp. 235-264.

[7] F. Shafizadeh, "Introduction to pyrolysis of biomass", in Journal of Analytical and Applied Pyrolysis, (1982), Vol. 3, pp. 283-305.

[8] T. Valliyappan, N. N. Bakhshi and A. K. Dalai, "Pyrolysis of glycerol for the production of hydrogen or syn gas", in Bioresource Technology, (2008), Vol. 99, pp. 4476-4483.

[9] K. D. Pathak, "Catalytic conversion of glycerol to valueadded liquid chemicals", Master's Thesis, University of Saskatchchewan, (2005).

[10] G. Simmons and M. Sanchez, "High-temperature gasification kinetics of biomass pyrolysis", in Journal of Analytical and Applied Pyrolysis, (1981), Vol. 3, pp. 161-171.
[11] G. W. Huber and J. A. Dumesic, "An overview of aqueousphase catalytic processes for production of hydrogen and alkanes in a biorefinery", in Catalysis Today, (2006), Vol. 111, pp. 119-132.

[12] M. V. Twigg, "Catalyst handbook", 2nd ed. Frome, England: Wolfe Publishing Ltd, (1989).

[13] X. Wang, M. Li, M. Wang, H. Wang, S. Li, S. Wang and $\mathrm{X}$. Ma, "Thermodynamic analysis of glycerol dry reforming for hydrogen and synthesis gas production", in Fuel, (2009), Vol. 88, pp. 2148-2153.

[14] H. Wang, X. Wang, M. Li, S. Li, S. Wang and X. Ma, "Thermodynamic analysis of hydrogen production from glycerol autothermal reforming", in International Journal of Hydrogen Energy, (2009), Vol. 34, pp. 5683-5690.

[15] N. Luo, X. Fu, F. Cao, T. Xiao and P. P. Edwards, "Glycerol aqueous phase reforming for hydrogen generation over Pt catalyst - Effect of catalyst composition and reaction conditions", in Fuel, (2008), Vol. 87, pp. 3483-3489.

[16] A. J. Byrd, K. K. Pant and R. B. Gupta, "Hydrogen production from glycerol by reforming in supercritical water over Ru/Al2O3 catalyst", in Fuel, (2008), Vol. 87, pp. 29562960.

[17] S. Adhikari, S. Fernando, S. R. Gwaltney, S. D. Filip To, R. Mark Bricka, P. H. Steele and A. Haryanto, "A thermodynamic analysis of hydrogen production by steam reforming of glycerol", in International Journal of Hydrogen Energy, (2007), Vol. 32, pp. 2875-2880.

[18] A. M. D. Douette, S. Q. Turn, W. Wang and V. I. Keffer, "Experimental investigation of hydrogen production from glycerin reforming", in Energy and Fuels, (2007), Vol. 21, pp. 3499-3504.

[19] S. Adhikari, S. D. Fernando and A. Haryanto, "Hydrogen production from glycerol: An update", in Energy Conversion and Management, (2009), Vol. 50, pp. 2600-2604.

[20] J. M. Encinar, J. F. González, G. Martínez and J. M. González, "Two stages catalytic pyrolysis of olive oil waste", in Fuel Processing Technology, (2008), Vol. 89, pp. 1448-1455.

[21] J. M. Encinar, J. F. González, G. Martínez and S. Román, "Catalytic pyrolysis of exhausted olive oil waste", in Journal of Analytical and Applied Pyrolysis, (2009), Vol. 85, pp. 197-203.

[22] Y. Goswami, "Renewable energy on the world stage", in Refocus, (2004), Vol. 5, pp. 60.

[23] M. C. J. Bradford and M. A. Vannice, "CO2 reforming of CH4 over supported Ru catalysts", in Journal of Catalysis, (1999), Vol. 183, pp. 69-75.

[24] D. Ferdous, A. K. Dalai, S. K. Bej and R. W. Thring, "Production of hydrogen and medium BTU gas via pyrolysis of a kraft lignin in a fixed-bed reactor", in Proceedings of the Intersociety Energy Conversion Engineering Conference, (2000).

[25] D. Sutton, B. Kelleher and J. R. H. Ross, "Review of literature on catalysts for biomass gasification", in Fuel Processing Technology, (2001), Vol. 73, pp. 155-173.

[26] M. Slinn, K. Kendall, C. Mallon and J. Andrews, "Steam reforming of biodiesel by-product to make renewable hydrogen", in Bioresource Technology, (2008), Vol. 99, pp. 5851-5858.

[27] H. Chen, Y. Ding, N. T. Cong, B. Dou, V. Dupont, M. Ghadiri and P. T. Williams, "A comparative study on hydrogen production from steam-glycerol reforming: thermodynamics and experimental", in Renewable Energy, (2011), Vol. 36, pp. 779-788.

[28] J. M. Encinar, J. F. González, J. J. RodrIguez and M. J. Ramiro, "Catalysed and uncatalysed steam gasification of eucalyptus char: influence of variables and kinetic study", in Fuel, (2001), Vol. 80, pp. 2025-2036.

[29] J. M. Encinar, J. F. González and J. González, "Steam gasification of Cynara cardunculus L.: influence of variables", in Fuel Processing Technology, (2002), Vol. 75, pp. 27-43. 